\title{
CrimRxiv
}

\section{Views on COVID-19 from inside prison: Perspectives of high-security prisoners}

David C. Pyrooz, Ryan M. Labrecque, Jennifer J. Tostlebe, Bert Useem

Published on: Jul 10, 2020

DOI: $10.21428 / \mathrm{cb} 6 \mathrm{ab} 371.1018 \mathrm{fgbf}$

License: Creative Commons Attribution-NonCommercial-NoDerivatives 4.0 International

License (CC-BY-NC-ND 4.0). 
Abstract: People confined in jail and prison are especially vulnerable to outbreaks of communicable diseases such as coronavirus disease 2019 (COVID-19). Corrections officials across the country have responded by shifting institutional practices, including suspending visitation and programming, as well as releasing some inmates early. Missing from leading accounts of COVID-19 in correctional facilities are the perspectives of prisoners. This study examined perceptions of risks and responses among a random sample of 31 high-security male prisoners in Oregon. In-depth interviews were conducted by phone in private attorney rooms between April and May. Mixed method data revealed that respondents felt it was a matter of when, not if, the disease would spread throughout the prison system, due primarily to transmission from correctional officers. Yet prisoners were not highly worried about contracting the disease. This was due, in part, to being physically and socially isolated in restrictive housing, which in this instance they viewed as advantageous. Respondents believed the threat of the virus was being taken seriously by prison officials but lacked confidence in their ability to prevent an outbreak or effectively treat infected prisoners. Strategies are needed to mitigate the spread, fear, and consequences of COVID-19 in correctional facilities, as this disease has the potential to upend the functions and purposes of the American prison.

Key Words: COVID-19; Prisons; Survey Research

Corresponding Author: David Pyrooz, PhD, Department of Sociology and Institute of Behavioral Science, University of Colorado Boulder, 483 UCB, Boulder, CO 80309 (david.pyrooz@colorado.edu)

Acknowledgments: Research reported in this publication was funded by the Charles Koch Foundation. It was also supported by a pilot grant from the Developmental Core of University of Colorado Population Center (CUPC), which is supported by the Eunice Kennedy Shriver National Institute of Child Health \& Human Development of the National Institutes of Health under Award Number P2CHD066613. The content is solely the responsibility of the authors and does not necessarily represent the official views of the Charles Koch Foundation or the National Institutes of Health.

\section{Introduction}

There are approximately 1,800 federal and state prisons in the United States (Sawyer and Wagner 2020). Correctional institutions serve many different purposes. At its core, their mission is to separate individuals - 1.5 million people, on any given day-convicted of serious crimes from society (Fleisher 1989). They also assume responsibility for ensuring the safety and well-being of these individuals, as well as maintaining orderly facilities (DiIulio Jr. 1987). An additional mission has been to rehabilitate prisoners and prepare them for returning to society (Cullen and Gilbert 2013). The purposes and functions of these institutions, however, have varied over time due to changing views about crime and 
punishment, the effectiveness of rehabilitation, and the role of prison in the criminal justice system (Pratt 2019).

Coronavirus 2019 (COVID-19) has the potential to upend the missions of the American prison system, as it represents a serious threat to the health and welfare of people who live and work in these facilities (Kinner et al. 2020; Stephenson 2020). Confined populations are vulnerable to outbreaks of communicable diseases. Overcrowding and restricted movement, inaccessible or poor quality health care, the high prevalence of chronic disease and comorbidity, and an aging custodial population exacerbate these risks (Akiyama, Spaulding, and Rich 2020; Maruschak, Berzofsky, and Unangst 2015; Novisky 2018). The most updated data indicate that nearly 30,000 prisoners have tested positive and 415 have died (Marshall Project 2020a). In response there have been calls to simultaneously reduce the prison population and restructure institutional practices (Nowotny et al. 2020). Given the intimate ties between correctional facilities and communities, prisons are a vector for managing and responding to this public health crisis (Montoya-Barthelemy et al. 2020).

Missing from the leading analyses on how to address the growing crisis of COVID-19 are the views of the prisoners themselves. Even though prisons are by their nature coercive institutions (Sparks, Bottoms, and Hay 1996), it is important to learn about the perspectives and experiences of those who are incarcerated. American prisons are typically a beehive of activity, and any response to COVID-19 requires cooperation from prisoners, or it runs the risk of civil disobedience, uprisings, or, worse, collective violence (Useem and Kimball 1991). In order to "establish best practices and facilitate public health functions," there is a need for more scientific research on COVID-19 in prisons (MontoyaBarthelemy et al. 2020:4). Furthermore, official reports and press coverage have only provided a partial glimpse of what is occurring within prison walls. The portrait painted thus far may misrepresent how prisoners are perceiving and managing the current pandemic, like other accounts of events in prisons, such as uprisings/riots or human experiments (Hornblum 2013; Thompson 2017). Interviews with prisoners are a way to overcome the partial accounts.

Based on interviews with prisoners, we sought to understand their experiences and perspectives on COVID-19 risks and responses. The research site for this study was a mixed custody level state prison. Unlike jails, where there is constant turnover as the confined population is awaiting trial or serving short sentences, prisons primarily house individuals convicted of felonies serving sentences exceeding one year. All prison systems have suspended normal visitation among other preventive measures (Marshall Project 2020b), which has also ceased in-person research, presenting researchers with serious challenges for continuing existing studies or conducting new studies on COVID-19. Our research strategy involved an alternative means of gathering data from institutional populations to learn about prisoners' perspectives and experiences of COVID-19. We relied on phone-based interviews, which were procedurally comparable to private attorney communications, to gather 
quantitative and qualitative data. The repercussions of COVID-19 are extensive, and our aim is to contribute to research (e.g., Ashby 2020; Mohler et al. 2020; Piquero et al. 2020) that seeks to understand the relevance of COVID-19 for criminology and criminal justice.

\section{Methods}

We conducted phone interviews between April 3 and May 18, 2020 with prisoners in the Oregon Department of Corrections (ODOC). As of April 1, 2020, there were approximately 14,500 adults confined in the ODOC, of whom more than $60 \%$ were convicted of violent offenses. We focused on highsecurity male prisoners housed in an Intensive Management Unit (IMU) at one facility who were subject to randomized housing assignment as part of an ongoing evaluation of a restrictive housing (i.e., solitary confinement) step-up program (SUP). Prisoners in the IMU are subject to prolonged periods of time-in-cell ( 23 hours/day), while time-in-cell is lower for those in the SUP ( 20 hours/day) who also maintain additional privileges such as extra recreation time, social interaction, and phone calls, as well as access to special programs and video games. High-security prisoners are an ideal population to interview for an investigation of this type because these individuals have experience in both general population and restrictive housing environments.

A random sample of 41 individuals constituted the three cohorts eligible for study participation. This sample was generated from a population of prisoners sentenced to a six-month term in the IMU for serious rule violations during the enrollment period. Seven individuals declined to leave their cell to permit inquiry into their participation in the study, while three individuals declined to interview at the consent stage. The authors conducted interviews by phone with 31 prisoners in private attorney rooms who provided verbal consent to study participation (75.6\% response rate, $91.2 \%$ participation rate). Interviews were audio-recorded with the permission of the respondent and transcribed to support data analysis. Study protocols were approved by the corresponding author's institution and the ODOC Research Committee.

Respondents were between ages 20 and 42 years $(M=30.9, S D=6.4)$ at the time of the interview. In terms of self-identified race/ethnicity, the sample was $52 \%$ white, $7 \%$ black, $36 \%$ Latino, $3 \%$ Native Hawaiian/Pacific Islander, and 3\% other/mixed. The custodial population of the entire ODOC is $72 \%$ white, $10 \%$ blacks, $14 \%$ Latino, and $5 \%$ other. Nearly forty percent of the sample indicated being legally employed in the six months prior to their current incarceration. Respondents reported between 7 and 14 years of educational attainment $(M=11.5, S D=1.5)$.

There were eight COVID-19-related questions added to the survey instrument in late March 2020, prior to the launch of data collection for the larger evaluation. Each of these items had a fixed response and an open-ended section to tap prisoners' views of their risks of contracting the disease and its outbreak in the unit, the prison system's response to disease and attendant consequences for prison 
programming. Whereas fixed response items assessed agreement with statements, open-ended responses items asked respondents to elaborate on their answers.

\section{Results}

Table 1 reports the perspectives of respondents on COVID-19, which we supplement with representative quotes. Given the nature of the sample, we only report general age ranges and the evaluation housing assignment (IMU or SUP) of the respondent for each associated quote.

\section{Table 1. Prisoners' Perspectives on COVID-19.}

\begin{tabular}{|c|c|c|}
\hline Self-Report Perspectives & $\mathrm{N}$ & $\%$ \\
\hline \multicolumn{3}{|l|}{$\begin{array}{l}\text { How worried are you that prisoners } \\
\text { at your institution will become } \\
\text { infected with COVID-19? }\end{array}$} \\
\hline $\begin{array}{l}\text { Either not at all or somewhat } \\
\text { worried }\end{array}$ & 23 & $74.2 \%$ \\
\hline Either pretty or extremely worried & 8 & $25.8 \%$ \\
\hline \multicolumn{3}{|l|}{$\begin{array}{l}\text { How likely is it that you will soon get } \\
\text { infected with the coronavirus? }\end{array}$} \\
\hline Unlikely & 20 & $64.5 \%$ \\
\hline Likely & 9 & $29.0 \%$ \\
\hline Don't know & 2 & $6.5 \%$ \\
\hline \multicolumn{3}{|l|}{$\begin{array}{l}\text { Do you think the Oregon prison } \\
\text { system is taking the threat of the } \\
\text { coronavirus seriously? }\end{array}$} \\
\hline No & 8 & $25.8 \%$ \\
\hline Yes & 23 & $74.2 \%$ \\
\hline $\begin{array}{l}\text { Do you think the prison system is } \\
\text { capable of preventing an outbreak of } \\
\text { the coronavirus? }\end{array}$ & & \\
\hline
\end{tabular}




\begin{tabular}{|c|c|c|}
\hline No & 13 & $41.9 \%$ \\
\hline Yes & 15 & $48.4 \%$ \\
\hline Don't know/missing & 3 & $9.7 \%$ \\
\hline \multicolumn{3}{|c|}{$\begin{array}{l}\text { If you were to get the coronavirus, do } \\
\text { you believe the prison system will } \\
\text { provide adequate treatment? }\end{array}$} \\
\hline No & 13 & $41.9 \%$ \\
\hline Yes & 14 & $45.2 \%$ \\
\hline Don't know & 4 & $12.9 \%$ \\
\hline \multicolumn{3}{|c|}{$\begin{array}{l}\text { Your current housing in IMU/SUP } \\
\text { helps protect you from the } \\
\text { coronavirus. }\end{array}$} \\
\hline Disagree & 5 & $16.1 \%$ \\
\hline Agree & 26 & $83.9 \%$ \\
\hline \multicolumn{3}{|c|}{$\begin{array}{l}\text { Has the coronavirus prevented you } \\
\text { from receiving programming? }\end{array}$} \\
\hline No & 9 & $29.0 \%$ \\
\hline Yes & 22 & $71.0 \%$ \\
\hline
\end{tabular}

Source: Sample is composed of 31 prisoners in the Oregon Department of Corrections, 2020.

Note: $I M U$ = intensive management unit; SUP = step up program.

\section{Perspectives on Risk}

About three-quarters of respondents did not express a serious concern about an outbreak of COVID-19 within the facility. At first glance this may appear counterintuitive, but many respondents indicated that they would not worry about what they have no control over, such as who enters the prison or the inevitability of the disease's spread within the prison system. 
It's going to happen. I'm not worried about it. It's just one of those things that's going to happen. The way it's spread, it's going to happen. (40s, SUP)

The contrast between the "keepers" and the "kept" was particularly strong, as respondents expressed worries over institutional practices. Some maintained a cynical view toward the prison system.

I'd say I'm somewhat worried, because if one gets it, they're all going to get it. You know what I mean? If one comes down sick with it from this institution, you know what I mean. These cops [correctional officers] here are like, rednecks. Man, they're going to be like, 'Oh, I can go to work, don't worry about it. Oh, I got some flu symptoms, I'm going to be all right.' I know how these officers are. (30s, IMU)

Others viewed the institutional response much more positively, which alleviated their worry about COVID-19.

I'm actually not at all worried. DOC is actually doing a really good job and making sure that staff doesn't come in. Even if they have the regular flu, they are not allowed to come in to work. And obviously none of the AICs [adults in custody] are leaving, so, I mean they are, but they're not coming back, or hopefully not. (40s, SUP)

Similar to general worries about the outbreak of COVID-19 at the facilities, most prisoners did not believe that they were personally get infected. In fact, under one-third of the prisoners believed it would happen to them. Among those that did, they cited the inevitability of the disease's spread, due primarily to prison staff who will bring it into the prison and eventually the specific pod.

We are interacting with officials 24/7. Sometimes they might just feel healthy enough or they might just forget to wear gloves. I'm not sure if they're getting tested and I'm not sure if anybody knows that they have it. So everything that we're getting from food to certain supplies, they're being handed by officials so I can be contaminated by any of these folks if they're not aware of the situation. You see what I'm saying? So I mean it can be, it can easy happen just like to anybody out there. (30s, SUP)

Those who did not believe they would become infected placed a great degree of confidence in their personal ability to thwart the disease. They referenced keeping themselves and their cells clean, avoiding shared telephones and tablets, and maintaining physical separation from other people. This respondent cited all of these reasons:

I will be by myself in my cell. I cleaned my house [cell] every day. I wipe everything down. I've been avoiding using the phone or the tablets lately, so that's good. Other than that, I just keep, like you said, we're isolated in the cell, but I try to keep my cell as clean as possible. (30s, IMU) 
Many even cited the disinfectant that was in the attorney room where our phone call took place as evidence of lessening the risk of spread. Toward the end of April all prisoners were distributed two masks, along with instructions for maintaining the masks. Others cited their strong immune systems, infrequency of illness, or lack of comorbidities, referencing news reports of those most likely to succumb to the disease.

\section{Perspectives on Responses}

Prisoners felt confident that the threat of COVID-19 was being taken seriously by the prison system, as evidenced by affirmative responses from three-fourths of respondents. Many referenced informational flyers that had been distributed by prison officials as the reason for their belief, which included advisement on best practices for staying healthy and protected, for example:

...the institution has released a newsletter giving us awareness that this epidemic is very concerning for the institution. The safety of everybody. And they have advised us to wash our hands to stay clean. . [W] e've been advised that this is going on, but nothing further than outside of that. (30s, SUP)

Built into these responses was the belief that newsletters were not enough, because the information reported is rather sparse and general to the prison system rather than being tailored to the context of the unit. In response to a question about the prison staff discussing institutional responses to the virus with them, a respondent commented on the information being shared:

I mean, not in a person to person thing, but they give us these little, I don't know what you call them, like little letters from the director. Well, not really what's going on. The only thing that they mentioned about what was going on was that someone caught the infection at a different prison here in Oregon, and also how to avoid spreading the disease, and they talked about how they're doing all they can do keep us updated. (20s, SUP)

Respondents recognized the difference between information transmitted from the top administration versus information shared within the unit.

I feel like our staff that work with us and that we see every day in our unit, we've all been kind of figuring it out all at the same time. It's sort of like we've all been...like when we first started hearing about it like, 'All this is just, you know, a scam, this is...' And then we've all been kind of getting, you know, filling it as every single day... [W]e've all been kind of getting educated at the same time about it every single day. Like, 'Hey, you know, there's been another case, always getting more, you know, it's getting more severe.' So we've been learning all kind of as a group every single day. (30s, SUP) 
Prisoners are rarely privy to information about decision-making in institutions specifically or the prison system generally. The feeling was that while transparency was valued, given the serious threat to prisoner safety, more was needed.

While many believed that the prison system was taking COVID-19 seriously, they were less confident in the ability of the ODOC to contain the disease or provide adequate medical treatment if they were to become infected. Some of this feeling reflected the overarching conditions of the pandemic.

Hell nah. Nah. No, I don't. I don't think so. No, not even the hospitals out there in the real world can combat this situation. If it spreads in here, man, people are, there's going to be a lot of people that's going to die. You know what I'm saying? Because there's no vaccine, there's not probably enough bed space and we touch everything here. (30s, SUP)

Many based their opinions about the capability of responding to the disease on their personal and vicarious experiences with medical staff.

I'm sure that they would do the bare minimum, but it seems like whenever people get sick here and stuff like that, it seems like the doctor doesn't really know what he's talking about. You could break your toe, and he's going to tell you to gargle salt water. It's just ridiculous. They don't actually work hard to treat people. (20s, IMU)

More generally, healthcare is inadequate in prisons, due to underfunding and comorbidities (Wilper et al. 2009). Prisoners, however, seemed to also see COVID-19 as so threatening and unique that it could warrant proportional attention from the prison system and its medical response.

This isn't like I got a broken leg and it might not heal correctly. This is if I keep having it, I can give it to the next person or to the next guard. So yeah, that would be one thing I do believe they would give you medical attention immediately and do what they could to help you out, which is rare. (30s, IMU)

Others cited suspicious deaths of young prisoners, such as a 27-year-old who died of the flu, as a sign that the prison system is ill-equipped to respond to COVID-19. Filing a lawsuit, however, was viewed as a reliable mechanism to gain the attention of the prison system.

\section{Physical Distancing in Prison}

More than three-fourths of prisoners believed their housing assignment in the IMU/SUP minimized their risk of infection. Prisoners infrequently tout the virtues of solitary confinement, but in the midst of a pandemic, they found it to be protective. 
I definitely think, I mean, this is the one time in my life I've been grateful to be in isolation. (30s, IMU)

I'm pretty much in the best position to not get it. Other than coming down here today [to speak with the interviewer], I haven't had contact with anyone in weeks. (20s, IMU)

Physical distancing is built into their housing, as they remain in their cell anywhere from 20-23 hours a day. Respondents indicated that, outside of correctional officers, there are simply few points of vulnerability for contraction.

...we're in the cell most of the time. The only time we leave the cell is on Sunday, Wednesday and Friday is the times we leave the cell, and we just go from the cells to the showers. We shower and then go straight back to the cells. Then, if you go outside, it's straight outside and then straight back to your cell. Everything's on the unit. The door to go outside is 20 feet from my door, and then the showers are also on the unit. (20s, IMU)

Many who agreed with this statement compared themselves to prisoners in the general population who may not reside in a single-cell and where physical distancing was nearly impossible.

More than mainline [general population], yeah. It's less exposed, less people, less crowded areas because not really ever in the crowd. (20s, SUP)

So I mean it's like, so I guess, you know, I'm guessing my chances are very, very slim due to that fact. So it's like the only way I'm thinking that I could ever get it, is if one of the guards end up bringing it in from the street, so if they get around somebody else. So I'm guessing that my chances are pretty small, based on that. Like if I was to be on mainline, then I guess my chances would be, I'm guessing, greater because I'd be around more people. (30s, SUP)

Still, prisoners recognize that they are not completely protected while in the IMU/SUP. Many mentioned the prison staff and food service as a source of infection.

It definitely limits my possibility catching it, but it doesn't protect me because, at the end of the day... I mean, if we didn't have any interaction with staff, yes. It definitely protects me because I'm locked in my cell and I'm away from all the germs and stuff. But with the staff, the way they serve our trays, the way they pass us things, no. Definitely not. They're the one... If there's an outbreak in this prison of coronavirus, it's going to be the staff's fault. (20s, IMU)

Although speculative, even those few additional hours in the prison yard or unit dayroom seemed to make SUP prisoners feel less protected, as they are exposed to others while exercising or hanging around in the dayroom. 


\section{Loss of Programming and Visitation}

The majority of prisoners identified changes in institutional practices associated with COVID-19 as disrupting programming activities in the unit, including counseling and education. Most who indicated that nothing had changed were in the IMU, where these opportunities were limited in the first place. One respondent stated:

...we can still come out and like play video games and hang out with our people in the day room for an hour a day and go out to the yard. But as far as the actual programming...we haven't been able to go in over a month as far as that, and the COs [correctional officers] haven't told us anything. (20s, SUP)

Another respondent made a similar point, highlighting the types of programs that have been suspended:

We're not doing GOGI [Getting Out by Going In]. We're not doing the step-up program. We're not doing my DBTs [Dialectical Behavioral Therapy], the DBT class, and that's the classes that I'm in that we haven't been able to take because of the coronavirus...the group that we have while being in the step-up program has been shut down. (20s, IMU)

Educational opportunities, while not completely shut down, were also disrupted.

I mean I was doing my GED and these instructors are not coming in no more...Four times a week that I interacted with this educational instructor briefly. So you know, a lot of it is inside [my cell] homework, so it doesn't really affect me. (30s, SUP)

Others related institutional changes to visitation, one of the most meaningful lifelines some prisoners maintain to the outside world.

They cut off visiting for obvious reasons. It's cut off til further notice, but that's why Telmate [a private company providing inmate phone calls] has been giving us free calls so we can still stay connected with our families because family is a big part of DOC and keeping sane. (20s, IMU)

Some maintained that when visitation was suspended, it indicated that COVID-19 was serious and the prison system was taking the threat seriously.

\section{Discussion}

The disruption caused by COVID-19 may result in the reorganization of many institutions, including family, the labor market, politics, education, and religion. It may also result in the restructuring of the American prison system, where more people than ever before are exposed to imprisonment, either 
personally or via family members (Enns et al. 2019). Gaining access to incarcerated populations to conduct research is challenging, especially among high-security prisoners; collecting such data in the midst of a pandemic poses even greater logistical and practical difficulties. The stakes are raised because prisoner populations are highly susceptible to the transmission of communicable diseases (Akiyama et al. 2020; Maruschak et al. 2015). While journalistic accounts and official reports offer insight, they lack systematic data on the perspectives of prisoners and may not adequately capture what is being experienced in U.S. prisons.

This study provides the first description of perceptions and views of COVID-19 from the perspective of prisoners. It is apparent from our data that COVID-19 is already altering the concerns of prisoners and the routines within the prison. Our respondents felt it was not a matter of if, but when, the virus would ultimately reach their facility, despite their belief that the prison authorities were taking the threat of the virus seriously and responding accordingly. Our respondents also did not express a great deal of worry about the spread of COVID-19 in their institution or believe that they would become infected. Neither of these findings are especially surprising. For the former, prisoners have little control over their circumstances beyond their immediate living arrangement; they recognized that they are subject to institutional practices. For the latter, prisoners expressed the view that the physical separation of restrictive housing decreased their risk of contracting the virus. There are welldocumented concerns about the psychological harms of isolation (Brooks et al. 2020), as well as placement in solitary confinement (Morgan et al. 2016; Reiter et al. 2020). In this instance, respondents saw their housing arrangement as beneficial, as they were less exposed to others than they would be in general population housing. Still, their reservations about infection were found primarily with contact with correctional officers, but also uncleanly surface areas or food delivery.

We acknowledge that our findings are limited to a small number of high-security prisoners from a single prison in Oregon, a system where there have only been 188 positive reports of COVID-19 as of May 27, 2020, which includes 39 prison staff (Oregon Department of Corrections 2020). It is possible that these results may not generalize to prisons with widespread outbreaks of COVID-19, other state prison systems, general population housing, or jails. Despite these limitations, this study provides critical insight into the perspectives and experiences of a difficult to reach and often overlooked population. And there are several implications that can be drawn from the study findings based on interviews with prisoners.

Preventing and intervening in the spread of COVID-19 within prison systems represents a crucial and pressing issue for corrections scholars, officials, and policymakers. One of the major obstacles in overcoming this challenge is that prisons do not permit physical distancing, as many are overcrowded and rely on double-bunks or dormitory housing. In response, some state prison systems have announced plans to reduce its population by refusing new admissions from county jails, transferring 
prisoners to parole or home confinement, and releasing individuals with serious underlying medical conditions or who are nearing the end of their sentence (Prison Policy Initiative 2020). Actual reductions in prison populations, however, have paled in comparison to jail populations ( $5 \%$ versus 30\%; Widra and Wagner 2020). Still, these represent meaningful reductions and could represent a turning point in the era of mass incarceration.

It is important to highlight that around $40 \%$ of prisoners nationwide are incarcerated for violent offenses (Sawyer and Wagner 2020), where early release forces prison officials to evaluate a different set of public safety issues than jail officials. There is furthermore the issue of where former prisoners, who have generally been incarcerated for longer periods of time than jail inmates, would go if returned to the community. While some may have homes or family members with whom they could reside, others may not. If individuals are released from prison only to return to the street or homeless shelters, their threat of contracting the virus may be similar or worse in these alternative environments (Tsai and Wilson 2020). Additionally, there are questions about where and how these individuals would go about receiving medical care in the community. In short, solutions to this problem entail complex tradeoffs.

The findings from our study identify several potential strategies that prison official may undertake to mitigate the circulation of COVID-19. These include screening and testing staff and prisoners for symptoms, providing masks and other protective gear to all staff and prisoners, regularly sanitizing living spaces and shared items (e.g., phones, tablets), safely preparing and delivering food, and minimizing unnecessary interpersonal contact. These actions would go to great lengths at curbing the spread of this disease in prison. Indeed, according to the New York Times, jails and prisons are among the leading hot spots for cases connected to COVID-19 in the United States (New York Times 2020). The prisoners we interviewed also expressed a desire for more frequent communication about the virus and real-time updates about the department's response to the pandemic. Such efforts may be beneficial for reducing prisoners' anxieties and fears about contracting the disease.

Additionally, since programs and visitations have been cancelled to minimize the risk of spreading the disease, prison officials should consider facilitating non-physical contact (e.g., telecommunication) for rehabilitative activities and visitation as this pandemic continues. Reducing recidivism is a nationwide priority, and finding ways to curb the impact of COVID-19 responses on programming (Jonson and Cullen 2015) and visitation (Mitchell et al. 2016) is crucial to this goal. This research study highlights the reality of these technological possibilities. Our research team, spread across the country, was able to speak with prisoners in the most secure location in the prison system. If this same strategy was employed for programming and visits, prisoners could continue to receive treatment services and maintain contact with their families as the pandemic continues. 
Finally, it may be prudent for prison systems to develop strategies for safely returning vulnerable prisoners back into the community sooner rather than later as the courts have demonstrated a willingness to intervene on these matters. On April 13, 2020, for example, prisoners at the Elkton Federal Correctional Institution-a low-security dormitory-style federal prison where COVID-19 was rapidly spreading - filed a class action habeas petition for relief from detention that violates their Eighth Amendment and seeking the immediate release, furlough, or transfer of individuals who are elderly or have an underlying condition (case no. 4:20-cv-794). On May 26, 2020, the Supreme Court upheld orders from a federal judge in Ohio on this case to expeditiously transfer hundreds of at-risk prisoners out of Elkton through a variety of methods (e.g., compassionate release, parole, furlough) (Barnes 2020). Such a ruling by the Supreme Court emphasizes the need for prison systems to act quickly with its responses to COVID-19 that are in the best interest of inmates, staff, and society. In our view, it is better for prison officials to proactively undertake policy reformations in deliberate and thoughtful ways, rather than waiting to be forced by a court order to modify practices without careful consideration being taken to mitigate the potential risks of such a change.

We conclude by emphasizing that there is tremendous variability across American prisons, including their composition, culture, and competencies. Reported cases of and deaths from COVID-19 have also been spread disproportionately across the United States, with more infections and losses found in coastal communities and major cities (Medina and Gebeloff 2020). These factors are likely to result in the unequal distribution of COVID-19 across prison systems, prisons, and prison units. A core aim of corrections scholars should be to understand the sources of this distribution. Wilson (1989:92), following in the footsteps of Phillip Selznick, discussed the importance of an organization's "distinctive competence," or the array of activities that define an organization's core competencies. The COVID-19 pandemic suggests the need for prison systems to develop a new competency: the control of infectious diseases behind bars while, at the same time, allowing the agency to fulfill its traditional missions. One can forecast that other pandemics will likely occur in the future, perhaps even more damaging and deadly than COVID-19.

As this study highlights, there is a need for social scientists to operate at the forefront of understanding criminal justice system response to COVID-19. In the matter of three months since stayat-home orders went into effect across the United States, criminologists have already begun documenting the impacts of COVID-19 on 911 calls for service, traffic stops, domestic violence, and Part I crimes (Ashby 2020; Mohler et al. 2020; Piquero et al. 2020). It is critical for the field to extend this understanding beyond the knowledge gleaned from official records, which means incorporating the perspectives and experiences of the populations subject to the control of the criminal justice system.

\section{References}


Akiyama, Matthew J., Anne C. Spaulding, and Josiah D. Rich. 2020. "Flattening the Curve for Incarcerated Populations - COVID-19 in Jails and Prisons." New England Journal of Medicine 382:207577.

Ashby, Matthew PJ. 2020. "Initial Evidence on the Relationship between the Coronavirus Pandemic and Crime in the United States." Crime Science 9(1):1-16.

Barnes, Robert. 2020. “Supreme Court Won't Stop Ohio Order for Prisoners to Be Moved or Released Because of Coronavirus." Washington Post. Retrieved May 29, 2020

(https://www.washingtonpost.com/politics/courts_law/supreme-court-for-now-will-not-stop-ohioorder-to-identify-prisoners-for-release-because-of-coronavirus/2020/05/26/8b6d458a-9f74-11ea-81bbc2f70f01034b_story.html).

Brooks, Samantha K., Rebecca K. Webster, Louise E. Smith, Lisa Woodland, Simon Wessely, Neil Greenberg, and Gideon James Rubin. 2020. “The Psychological Impact of Quarantine and How to Reduce It: Rapid Review of the Evidence." The Lancet 395:912-20.Cullen, Francis T., and Karen E. Gilbert. 2013. Reaffirming Rehabilitation. Waltham, MA: Anderson.

DiIulio Jr., John J. 1987. Governing Prisons: A Comparative Study of Correctional Management. New York, NY: The Free Press.

Enns, Peter K., Youngmin Yi, Megan Comfort, Alyssa W. Goldman, Hedwig Lee, Christopher Muller, Sara Wakefield, Emily A. Wang, and Christopher Wildeman. 2019. "What Percentage of Americans Have Ever Had a Family Member Incarcerated?: Evidence from the Family History of Incarceration Survey (FamHIS)." Socius 5:2378023119829332.

Fleisher, Mark S. 1989. Warehousing Violence. Newbury Park, CA: Sage.Hornblum, Allen M. 2013. Acres of Skin: Human Experiments at Holmesburg Prison. New York: Routledge.

Johnson, Cheryl Lero, and Francis T. Cullen. 2015. "Prisoner Reentry Programs." Crime and Justice 44(1):517-75.

Kinner, Stuart A., Jesse T. Young, Kathryn Snow, Louise Southalan, Daniel Lopez-Acuña, Carina Ferreira-Borges, and Éamonn O'Moore. 2020. "Prisons and Custodial Settings Are Part of a Comprehensive Response to COVID-19." The Lancet. Public Health.

Marshall Project. 2020a. "A State-by-State Look at Coronavirus in Prisons." The Marshall Project. Retrieved May 1, 2020 (https://www.themarshallproject.org/2020/05/01/a-state-by-state-look-atcoronavirus-in-prisons). 
Marshall Project. 2020b. “Coronavirus Tracker: How Justice Systems Are Responding in Each State.” The Marshall Project. Retrieved April 10, 2020

(https://www.themarshallproject.org/2020/03/17/tracking-prisons-response-to-coronavirus).

Maruschak, Laura M., Marcus Berzofsky, and Jennifer Unangst. 2015. Medical Problems of State and Federal Prisoners and Jail Inmates, 2011-12. Washington, D.C.: U.S. Department of Justice, Bureau of Justice Statistics.

Medina, Jennifer, and Robert Gebeloff. 2020. “The Coronavirus Is Deadliest Where Democrats Live." The New York Times, May 25.

Mitchell, Meghan M., Kallee Spooner, Di Jia, and Yan Zhang. 2016. “The Effect of Prison Visitation on Reentry Success: A Meta-Analysis." Journal of Criminal Justice 47:74-83.

Mohler, George, Andrea L. Bertozzi, Jeremy Carter, Martin B. Short, Daniel Sledge, George E. Tita, Craig D. Uchida, and P. Jeffrey Brantingham. 2020. "Impact of Social Distancing during COVID-19 Pandemic on Crime in Los Angeles and Indianapolis." Journal of Criminal Justice 101692.

Montoya-Barthelemy, Andre, Charles D. Lee, Dave Cundiff, and Eric Smith. 2020. "Covid-19 and the Correctional Environment: The American Prison as a Focal Point for Public Health." American Journal of Preventive Medicine.

Morgan, Robert D., Gendreau, Paul, Smith, Paula, Gray, Andrew L., Labrecque, Ryan M., MacLean, Nina, Van Horn, Stephanie A., Bolanos, Angelea D., Batastini, Ashley B, and Mill, Jeremy F. 2016. "Quantitative Syntheses of the Effects of Administrative Segregation on Inmates' Well-Being." Psychology, Public Policy, and Law 22:439-61.

New York Times. 2020. "Coronavirus in the U.S.: Latest Map and Case Count." The New York Times, May 4.Novisky, Meghan A. 2018. "Avoiding the Runaround: The Link between Cultural Health Capital and Health Management among Older Prisoners." Criminology 56(4):643-678.

Nowotny, Kathryn, Zinzi Bailey, Marisa Omori, and Lauren Brinkley-Rubinstein. 2020. “COVID-19 Exposes Need for Progressive Criminal Justice Reform." American Journal of Public Health e1-2.

Oregon Department of Corrections. 2020. "COVID-19 Status at Oregon Department of Corrections Facilities." Retrieved April 15, 2020 (https://www.oregon.gov/doc/covid19/Pages/covid19tracking.aspx).

Piquero, Alex R., Jordan R. Riddell, Stephen A. Bishop, Joan A. Reid, and Nicole Leeper Piquero. 2020. "Staying Home, Staying Safe? A Short-Term Analysis of COVID19 on Dallas Domestic Violence." American Journal of Criminal Justice. 
Pratt, Travis C. 2019. Addicted to Incarceration: Corrections Policy and the Politics of Misinformation in the United States. Thousand Oaks, CA: Sage.Prison Policy Initiative. 2020. “Virus Response.” Retrieved April 15, 2020 (https://www.prisonpolicy.org/virus/virusresponse.html).

Reiter, Keramet, Joseph Ventura, David Lovell, Dallas Augustine, Melissa Barragan, Thomas Blair, Kelsie Chesnut, Pasha Dashtgard, Gabriela Gonzalez, and Natalie Pifer. 2020. "Psychological Distress in Solitary Confinement: Symptoms, Severity, and Prevalence in the United States, 2017-2018." American Journal of Public Health 110(S1):S56-S62.

Sawyer, Wendy, and Peter Wagner. 2020. Mass Incarceration: The Whole Pie 2020. Prison Policy Initiative.Sparks, Richard, Anthony E. Bottoms, and Will Hay. 1996. Prisons and the Problem of Order. Clarendon Press Oxford.

Stephenson, Joan. 2020. "COVID-19 Pandemic Poses Challenge for Jails and Prisons." JAMA Health Forum 1(4):e200422-e200422.Thompson, Heather Ann. 2017. Blood in the Water: The Attica Prison Uprising of 1971 and Its Legacy. New York: Vintage.

Tsai, Jack, and Michal Wilson. 2020. "COVID-19: A Potential Public Health Problem for Homeless Populations." The Lancet Public Health 5(4):e186-87.

Useem, Bert, and Peter Kimball. 1991. States of Siege: US Prison Riots, 1971-1986. New York: Oxford University Press.

Widra, Emily, and Peter Wagner. 2020. "While Jails Drastically Cut Populations, State Prisons Have Released Almost No One." Retrieved May 29, 2020

(https://www.prisonpolicy.org/blog/2020/05/14/jails-vs-prison-update/).

Wilper, Andrew P., Steffie Woolhandler, J. Wesley Boyd, Karen E. Lasser, Danny McCormick, David H. Bor, and David U. Himmelstein. 2009. "The Health and Health Care of US Prisoners: Results of a Nationwide Survey." American Journal of Public Health 99(4):666-72.

Wilson, James Q. 1989. Bureaucracy: What Government Agencies Do and Why They Do It. New York: Basic Books.

\section{Footnotes}

1. https://www.acluohio.org/wp-content/uploads/2020/04/2020-04-13-001-Petition-for-Writ-ofHabeas-Corpus-1.pdf $\underline{\underline{H}}$ 